\title{
The profile of the expression of IBMR3 antigens 3T3 and HT29 cancer cell line after analysis
}

\author{
Qutaiba Kafi Jassim Alrawi \\ Laboratory Department, faculty of Medicine Technology of Surman, Alzawiah University, Surman, Libya
}

\section{Email address:}

qkalrawi@yahoo.com

\section{To cite this article:}

Qutaiba Kafi Jassim Alrawi. The Profile of the Expression of IBMR3 Antigens 3T3 and HT29 Cancer Cell Line after Analysis. Science Research. Vol. 2, No. 4, 2014, pp. 55-61. doi: 10.11648/j.sr.20140204.11

\begin{abstract}
Aims: The aim of this study was to evaluate the effectiveness of specific monoclonal IBMR3 antibodies expression in the cancer cell lines of 3T3 and HT29, in order to recognize specific antigen and make evaluation, using immunoblotting technique which is widely use in this filed. Methods: Protein extracts were extracted from these cancer cell lines and used for western bloat. The Immunobloting were consequently subjected to densitometry analysis using bioimaging machine. This bioimaging process will facilitate to measure the molecular weights, peak height and raw volume of the protein bands for the 3T3 and HT29 cancer cell lines, which helps in diagnosis of any pathogenic antigen. Results: The bands obtained from bioimaging were exposed on the PVDF membrane. In the 3T3 bio imaging process revealed four bands and molecular weight were 299.58, 87.90, 41.67 and 23.54 KDa. However, bioimaging results for HT29 revealed also four bands with molecular weights: $90.11,41.31,23.87$ and $20.86 \mathrm{KDa}$. The results of Peak height densitometry for IBMR3 antigen bands for 3T3 were: 1856.985, 551.769, 394.164, and 216.185. However HT29 peak height results were: 281.544, 101.711.202.668, 757.213. The raw volume (amount of protein bands of IBMR3 Ag for 3T3) were: 1460168.75, 206078.47, 161406.89, and 219583.16. However HT29 raw volume results were: 110197.11, 76106.84, 98632.59, and 221395.34. Negative protein staining for 3T3 and HT29 cancer cell line bands were done by using mouse IgM serotype. IgM serotype was not indicated that means no specific antigens for negative control IgM. Conclusion: The bioimaging revealed different results of the expression profile in molecular weight, peak height and raw volume between the two cancer cell lines. The results from this study suggest that the IBMR3 antigens were differentially expressed in 3 T3 and HT29 and the molecular weight is higher in the 3T3 than HT29 cancer cell lines. In future it will be beneficial to categorize and study the character analysis of the IBMR3 antigen and its prospective role in cancer cells.
\end{abstract}

Keywords: 3T3 (Mouse Fibroblast) Cell Line and HT29 (Human Colorectal) Carcinoma Cancer Cell Line, SDS-Page, Monocloncal Antibodies, MAb IBMR3, Immunobloting, Bioimaging

\section{Introduction}

Monoclonal antibodies are being increasingly used for therapy, laboratory research and diagnosis. It was suggested to use of synthetic peptides equivalent to amino acid sequence proteins to the raising numerous antibodies (Walter and Doolittle, 1983). Monoclonal antibodies (mAb or moAb) are monospecific antibodies that are the same because they are made by identical immune cells that are all clines of a unique parent cell, in contrast to polyclonal antibodies which are made from several different immune cells. Monoclonal antibodies have monovalent affinity, in that they bind to the same epitope. IBMR3 is a $\mathrm{mAb}$ of IgM isotype produced in Advanced Medical and Dentil Institute / USM for research only, previously produced by using synthetic peptides corresponding to selected amino acid sequences of the IL-4 receptor molecules (Mat, 1992: Galizzi et al., 1990). mAb can only be produced in certain strains of mouse or rat with histo-compatibility plasmacytoma fusion lines (Hara and Mat, 2004). These mice or rat have normal basal levels of IgM and of IgG isotopes with normal B and T-cell development (Molina et al., 1996).

MAb, produced by B-cell clones of a single hybridoma or single parent cell line as a single type of antibody. In laboratory cultures media can produce hybridoma cell line from the fusion between one cell of normal B lymphocyte 
and a myeloma cell using special media (PEG) (poly ethyleneglycol) and HAT (hypoxanthine Aminopterin Thymidine) (Hawkins et al., 1992). Hara and Mat, 2004, IBMR3 mAb provided evidences that might be familiar with the same epitope which is shared by molecules having different molecular masses.

$\mathrm{MAb}$ has ability to generate against all antigens target, purified and split into fragments. MAb has a special character to conjugate with radio nuclides, toxins, drugs or enzymes. By nature, $\mathrm{mAb}$ originate from one specific clone with higher specificity, purity, reliability and identify only one epitope of the antigen. However, these antibodies have need of secondary antibodies which are used in two analyses (Spinks, 2000). Such methods are used in laboratories for common techniques in many medical research and diagnostics (Hawkins et al., 1992).

$\mathrm{MAb}$ has been widely used in immunotherapeutic because they assist with immune system cell molecules to produce anti-tumor responses and has the ability to increase the strength of immune reactions against tumor by Ligand formation with receptors on lymphocytes cells or antigenpresenting cells (Murillo et al., 2003). Antigen proteins which involved in the immune reaction can be separate via electrophoresis according to the molecular weight of their polypeptide chains (Shapiro et al., 1967). To confirm further the antibody specificity for the proteins western blotting is the most ideal technique practiced in Immunology and Microbiology (Stryer, 1996).

$\mathrm{MAb}$ are potentially competent of multiple functions. Successful as anticancer $\mathrm{mAb}$ has a special role in binding to an appropriate antigen in quantities adequate to mediate a disease-relevant response. Antibody has directly action power to destroy any target after conjugated radioactive isotopes or toxins, or antibody triggered apoptosis or indirect action power by activation of immune system components or blockade of critical receptors (Reichert and Valge-Archer, 2007). The main aim of this study was to analyses the antigen specific expression of specific monoclonal IBMR3 antibodies in the cancer cell lines 3 T3 and HT29 as main cells.

\section{Materials and Methods}

\subsection{Preparation of $3 T 3$ (Mouse Fibroblast) Cell Line}

The cells were harvested using cell dissociation solution $3 \mathrm{ml} / 25 \mathrm{~cm}^{2}$ flask or $5 \mathrm{ml} / 75 \mathrm{~cm}^{2}$ flask for about $15-20$ minutes for cells to dissociate and monitored under the microscope for floating cells.

The solution was decanted and the flask was tapped to lose the cells. Then $10 \mathrm{ml}$ of phosphate buffer saline (PBS) sterile solution were added and flushed inside the flask bottom to lose the cells. The cells were pipetted into a 15 $\mathrm{ml}$ sterile falcon tube and spin under 2,000 rpm for 5 minutes and then removed the PBS. The cells were washed twice with PBS and centrifuged. Then, PBS removed and the cells were frozen at $-20^{\circ} \mathrm{C}$.

\subsection{Preparation of HT29 Cell Culture Human Colorectal Carcinoma Line}

The cells were harvested using cell dissociation solution $3 \mathrm{ml} / 25 \mathrm{~cm}^{2}$ flask or $5 \mathrm{ml} / 75 \mathrm{~cm}^{2}$ flask for about $15-20$ minutes for cells to dissociate and (monitor under the microscope for floating cells). The solution was decanted and the flask was tapped to lose the cells.

Then $10 \mathrm{ml}$ PBS sterile solution were added and flushed inside the flask bottom to loosen the cells. The cells were pipetted into a $15 \mathrm{ml}$ sterile falcon tube to spin under 2,000 rpm for 5 minutes and then PBS decanted. The cells were washed two times with PBS and centrifuged and then decanted again and the cell was kept frozen at $-20^{\circ} \mathrm{C}$.

\subsection{Samples Preparation for Protein Quantification}

HT29 and 3T3 were subjected to lysis with mammalian cell lysis Kit (SIGMA, product code MCL1).

After the frozen sample cells were thawed at room temperature before lysis. Care was taken to ensure homogeneity of the samples. The samples of HT29 and 3T3 cell line were subjected to lysis in SIGMA Mammalian Cell Lysis Kit.

\subsection{Determination of Protein in, 3T3and HT29 (Cell Lines) Samples}

$15 \mu \mathrm{l}$ of the sample protein extract of 3T3 and HT29 was placed in an Eppendorf ${ }^{(B)}$ tube; the tests were done in duplicate.

Table 1. Method of quantification of protein for 3T3, HT29 by spectrophotometery

\begin{tabular}{|c|c|c|}
\hline Sample & HT29 & $3 \mathrm{T3}$ \\
\hline Sample Volume / $\mu 1$ & 15 & 15 \\
\hline Precipitant / $\mu \mathrm{l}$ & 500 & 500 \\
\hline \multicolumn{3}{|l|}{ Vortex and incubate $2-3 \mathrm{~min}$ at $\mathrm{RT}$} \\
\hline Co precipitant & 500 & 500 \\
\hline \multicolumn{3}{|l|}{ Mix briefly by vortex mixer } \\
\hline \multicolumn{3}{|l|}{ Centrifuged at $15000 \mathrm{rpm}$ for $5 \mathrm{~min}$} \\
\hline \multicolumn{3}{|l|}{ Take pellet after decanting supernatant } \\
\hline Add $400 \mu 1 \mathrm{H} 2 \mathrm{O}+100 \mu 1$ Copper solution & 500 & 500 \\
\hline \multicolumn{3}{|l|}{ Vortex Briefly to dissolve the precipitated protein } \\
\hline \multicolumn{3}{|l|}{$\begin{array}{l}\text { Added } 1 \mathrm{ml} \text { of working color reagent to each tube mix by } \\
\text { vortex }\end{array}$} \\
\hline \multicolumn{3}{|l|}{ The samples mixed for few second } \\
\hline $\begin{array}{l}\text { Absorbance of each sample and standard at } 480 \mathrm{~nm} \text { was } \\
\text { read }\end{array}$ & & \\
\hline
\end{tabular}

$50 \mu 1$ precipitant was added to each tube (including the standard curve tube), vortexed briefly and incubated for 2-3 min at room temperature. $500 \mu 1$ co-precipitant was added to each tube and briefly vortexed. The tubes were centrifuged at $10,000 \mathrm{x} \mathrm{g}$ for $5 \mathrm{~min}$, and then removed. The supernatants were decanted and immediately centrifuged and all the remaining water was removed from the pellet 
using micropipette. The pellet contained the proteins.

Copper solution $(100 \mathrm{ml})$ and $400 \mu \mathrm{l}$ of distilled water were added to each Eppendorf ${ }^{\circledR}$ tube, vortexed briefly to dissolve the precipitated protein. Working color reagent I $\mathrm{ml}$ was added to each Eppendorf ${ }^{(\mathbb{R})}$ tube, mixed on a vortex shaker and incubated at room temperature for 15-20 min.

The absorbance of each sample and standard was read at $480 \mathrm{~nm}$ using water for blank as a reference. The absorbance readings were taken within 40 minute after addition of the working color reagent.

Standard curve of BSA was drawn on Microsoft Excel ${ }^{\circledR}$. It depends on the relationship between standard (BSA) concentrations and absorbance reading in a spectrophotometer. Unknown samples of protein concentrations were calculated. The preparation is shown in Table 1.

\subsection{SDS-PAGE}

\subsubsection{Materials and Apparatus for SDS-PAGE}

The materials and chemicals for SDS-PAGE were of analytical grade and includes acrylamide (R \& Mchemical), N'N'-bis-methylene-acrylamide, electrophoresis (Sigma).

SDS (Fisher chemicals), deionized water 18.2 M $\Omega$-oM (Mega Om), Tris base (R \& M chemicals), 1.5 M Tris-HCL 8.8 (R \& M Chemicals), 0.5 M Tris- HCL 6.8(R \& M Chemicals ), 6 NHCL (Labscan), glycerol (R\&Mchemicals), bromo phenol blue(R \& M chemicals), B-Mercaptoethanol (Sigma Aldrich), glycine (Fisher chemicals), ammonium persulfate (R\&M chemicals), TEMD (Amersham Biosciences ), $\mathrm{NaOH}$ (sodium hydroxide)(Systerm ${ }^{\circledR}$ ), Laemmli sample buffer (SDS reducing buffer)(Bio Rad), protein extract from 3T3 and HT29, 0.25\% Coomassie brilliant blue R- 250 (Biochemical), protein ladder (protein maker) (BIO RAD Precision plus) and protein Kit 2-D Quant Kit (Amersham Biosciences).

The apparatus for SDS-PAGE were of analytical grade and includes electrophoresis

(Biorad $\left.{ }^{\circledR}\right), 3$ cell assembly and sample loading (MiniPROTEAN), pH Meter (HI 223 Calibration check Microprocessor), balance (Horizon Land Bhd.), water bath (Memmert), magnetic stirrer, pipette and beakers.

Electrophoresis was carried out in accordance with manufacturer's advice (BioRAD). For isolation of protein, $12 \%$ SDS poly acrylamide gel was prepared according to manufacturer's advice (Mini - PROTEAN®) 3Cell, Bio- Rad

The buffer system was used as described in (Laemmli, 1970), as wet electrophoretic transfer, gave acceptable results in short time (as little as 4 hours) (Towbin et al., 1979). SDS-PAGE was used to separate supernatant substances to produce short peptide chains that tend to elicit antibodies which recognized only the denatured form of the protein (Boersma et al., 1988).

\subsubsection{Preparation Protein Samples for SDS-PAGE}

After the samples were stored at $-20 \mathrm{C}^{\mathrm{o}}$ and latter subjected to preparation of protein sample for SDS-PAGE. The Lysis of cells was done by using mammalian cell lysis
(RIPA) buffer Kit (SIGMA, product code MCL1). The sample was vortexed in vortex shaker for 5 minute and then centrifuged to pellet the cellular debris. Protein rich supernatant was removed and decanted the pellet. Quantification of protein concentration was done using Amersham biosciences 2-D Quant Kit. The protein samples from cell lines then take in uniform concentration with Laemmli sample buffer $\left(\right.$ Bio-Rad $\left.^{\circledR}\right)$ as described by (Laemmli, 1970).

Samples were boiled to denature protein of antigen before loaded in electrophoresis $12 \%$ SDS-PAGE. The main purpose of denaturing of antigen protein was to produce short peptide with straight chains that tend to elicit antibodies which recognized only the denatured form of the protein (Boersma et al., 1988). Poly acrylamide gel was used for the process of electrophoresis (Towbin et al., 1979); the time duration for electrophoresis was 90 minute at 120 Volts.

\subsection{Western Blot}

\subsubsection{Chemical Materials and Apparatus}

The materials and chemical for western blot were of analytical grade and includes

$25 \mathrm{mM}$ Tris - $\mathrm{HCl}$ (R\&M Chemicals ), $192 \mathrm{~m} \mathrm{M}$ glycine(Fisher chemicals), $20 \%$ methanol (Sigma), distilled water (Barnstead), Tris base (R\&M Chemicals), $\mathrm{NaCl}$ (R\&M Chemical), Tween 20LABCHEM / AJAX CHEMICALS and skimmed milk.

The reagents for western blot were of analytical grade and includes (IBMR3) supernatant (hybridoma supernatant), secondary anti body (rabbit anti mouse IgS $(\mathrm{H}+\mathrm{L})$ -

HRP \& goat anti mouse Igs- HRP) (ZYMED) Invitrogen immunodetection, DAB substrate (Invitrogen) and Ponceau $\mathrm{S}$ stain (Sigma).

The apparatus for western blot also were of analytical grade and includes Mini Trans Blot Electrophoretic Transfer Cell (BIO RAD), two filter papers (Invitrogen), two-fiber pads (Invitrogen), $\mathrm{pH}$ Meter (Hanna Instrument), magnetic stirrer, PVDF membrane (Invitrogen) and the Belly Dancer shaker (Stovil Greensboro NC USA).

\subsubsection{Western Blot}

The protein bands on SDS-PAGE for 3T3 and HT29 cell lines, were transfer to PVDF membrane according to Kaspar protocols (Kaspar, 1997). The transfer was performed at $200 \mathrm{~mA}$ for 110 minute depending on the size of protein molecules.

\subsubsection{Immuno Blotting}

The membrane was blocked with skimmed milk over shaker then incubated with primary IBMR3 mouse mAb and then incubated with secondary antibody: rabbit anti mouse immunoglobulin IgS labeled with peroxidases incubated with Di amino benzyl dihydro chloride (DAB) substrate until the brown color appears. On the appearance of the brown color the membrane was washed with water to stop the reaction from further proceeding. 


\subsubsection{BioImaging Machine}

The membrane was placed in the BioImaging machine under normal light. The analysis of the specific IBMR3 antigen band was done to get the molecular weight, peak height and raw volume for the molecular band of IBMR3 Ag by densitometry.

\subsubsection{Negative Control Mouse IgM}

Mouse serum IgM was used as negative control for the IBMR3 antigen, concentration $2.5 \mathrm{mg} / \mathrm{ml}$ (lot number 51202537, ZYMED, USA)

\section{Results}

\subsection{Detection of IBMR3 Antigen in $3 T 3$ and HT29 Cancer Cell Lines}

\subsubsection{The Results of $3 T 3$ and HT29 Cancer Cell Lines of IBMR3 Antigens}

3 T3 and HT29 cancer cell lines of IBMR3 antigens proteins were analysis; the concentrations were quantified for samples using the same experimental conditions with same concentrations. The absorbance of samples and optic density were detected using a spectrophotometer. The concentration for the protein of 3T3 (2.569) $\mu \mathrm{g} / 1 \mu \mathrm{l}$ and HT29 (3.328) $\mu \mathrm{g} / 1 \mu \mathrm{l}$ as in table 2 .
Table 2. Spectrophotometer reading of standard BSA sample

\begin{tabular}{cccc}
\hline $\begin{array}{l}\text { Number of } \\
\text { Sample }\end{array}$ & $\begin{array}{l}\text { BSA } \\
\text { volume } \boldsymbol{\mu l}\end{array}$ & $\begin{array}{l}\text { Concentration } \\
\mathbf{2} \boldsymbol{\mu g} / \boldsymbol{\mu l}\end{array}$ & $\begin{array}{l}\text { O.D. } \\
\text { Spectrophotometer } \\
\text { reading }\end{array}$ \\
\hline 1 & 0 & 0 & 0.798 \\
2 & 5 & 10 & 0.777 \\
3 & 10 & 20 & 0.684 \\
4 & 15 & 30 & 0.605 \\
5 & 20 & 40 & 0.525 \\
6 & 25 & 50 & 0.464 \\
\hline
\end{tabular}

$\mathrm{BSA}=$ Bovine serum albumen, $\mathrm{OD}=$ Optical density

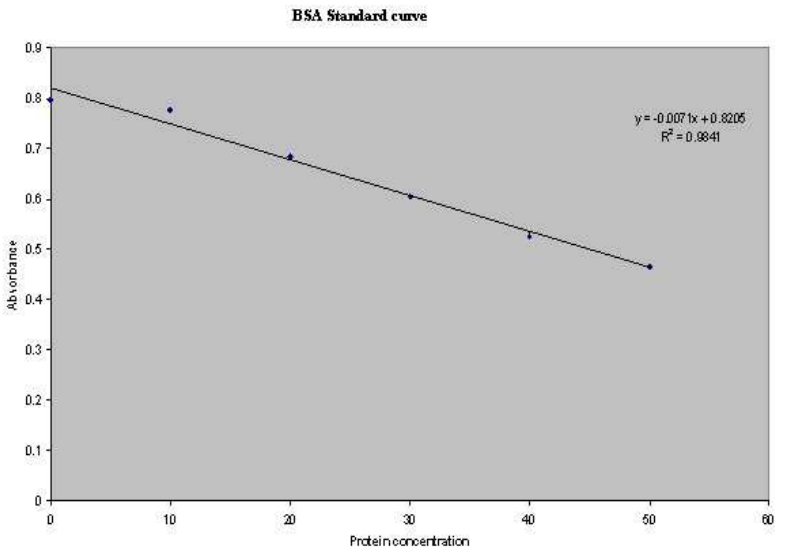

Figure 1. BSA standards curve

Table 3. Unknown cell line samples spectrophotometer absorbance and protein concentration reading

\begin{tabular}{lllllll}
\hline $\begin{array}{l}\text { Rank of } \\
\text { conc }\end{array}$ & $\begin{array}{l}\text { Samples cell } \\
\text { lines }\end{array}$ & $\mathbf{1}^{\text {st }}$.OD reading A. & $\begin{array}{l}\mathbf{2}^{\text {nd }} \text {.OD } \\
\text { reading A }\end{array}$ & $\begin{array}{l}\text { Mean } \\
\text { reading }\end{array}$ & \multicolumn{2}{l}{$\begin{array}{l}\text { Protein concentration } \\
\boldsymbol{\mu g} / \mathbf{1 5} \boldsymbol{\mu l}\end{array}$} \\
\hline 1 & HT29 & 0.562 & 0.370 & 0.466 & 46.929 \\
2 & $3 T 3$ & 0.500 & 0.447 & 0.4735 & 38.536 \\
\hline
\end{tabular}

OD: optic density

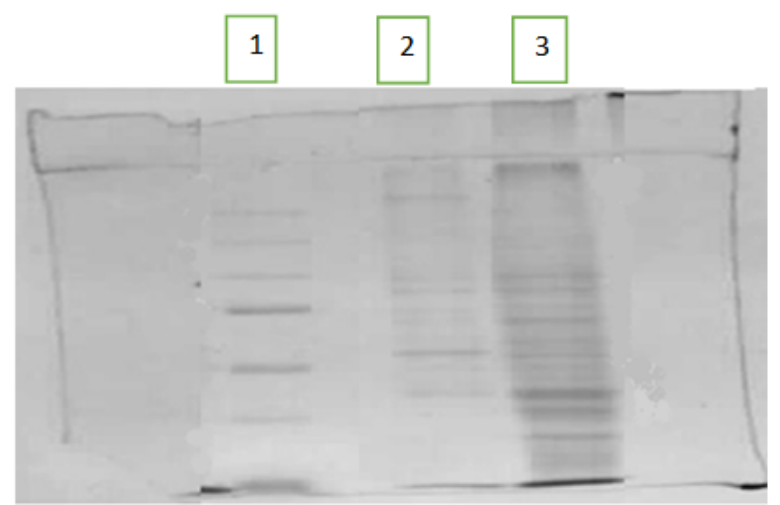

Figure 2. Gel electrophoresis for Densitometry analysis of (HT29 and 3T3) IBMR3Ag, 1 (PM), 2 (3T3), 3 (HT29)

Equal concentrations of proteins from each sample were subjected in wells and separated by SDS-PAGE $12 \%$ as in figure 2, the bands were transferred on to PVDF membrane, and probed with mab IBMR3. The expressions profiles of the antigens recognized by the antibody were different showing the cell line band samples under bioimaging machine as in figure 3.

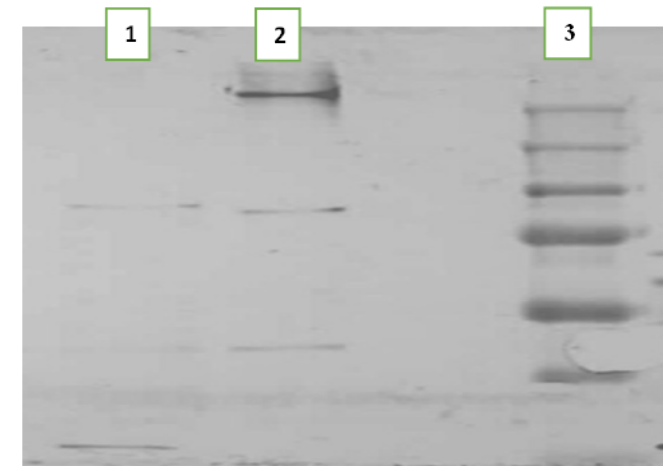

Figure 3. cancer cell line IBMR3 Ag: Western bloat (1) HT29, (2) 3T3, (3) protein marker bands on PVDF membrane

\subsubsection{Results of $3 T 3$ and HT29 Samples for Negative Control}

Negative protein staining for 3T3 and HT29 samples were done by using mouse IgM serotype with secondary antibody rabbit anti mouse IgS conjugated with (HRP) horse radish peroxidase as in (Figure 4 ), IgM serotype were not indicated that means no specific antigens for negative control IgM, 
these findings authenticate the results mention in figure 3 that prove all immunoblotting connections between IBMR3 mAb with specific of antigen epitopes in different antigens in 3T3 and HT29 cancer cell line .

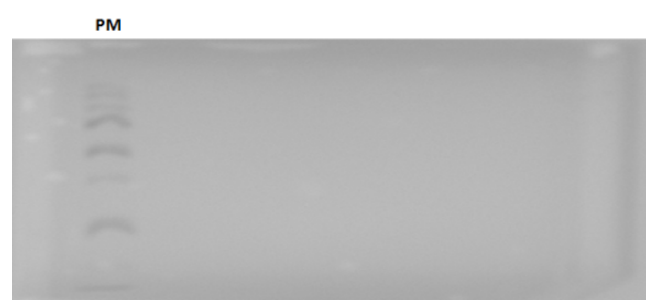

Figure 4. PVDF negative control only $(P M)$ protein marker was indicated
The expression of IBMR3 antigens in each band of two samples were analyzed by densitometry. Different results were observed for each band that included the molecular weight, peak height and raw volume, as shown in Table 4 and Figure 5.

HT29 IBMR3 Ags showed four different significant bands of MW (90.11, 41.31, 23.87, and 20.86) kDa.

3T3 IBMR3 Ags showed four different significant bands of MW (299.58, 87.90, 41.67, and 23.54) kDa.

The first band for 3T3 cell line regards the significant value of molecular weights between the bands of two samples, has the highest molecular weight of (299.58) KDa.

Table 4. Densitometry analysis of IBMR3 Ag in $3 T 3$ and HT29 cell line samples

\begin{tabular}{|c|c|c|c|c|c|}
\hline & & 1 & 2 & 3 & 4 \\
\hline \multirow{3}{*}{ 3T3cell line } & MW(KDa) & 299.58 & 87.90 & 41.67 & 23.54 \\
\hline & Raw volume & 1460168.75 & 206078.47 & 161406.89 & 219583.16 \\
\hline & Peak height & 1856.985 & 551.769 & 394.164 & 216.185 \\
\hline \multirow{3}{*}{ HT29cell line } & MW (KD a) & 90.11 & 41.31 & 23.87 & 20.86 \\
\hline & Raw volume & 110197.11 & 76106.84 & 98632.59 & 221395.34 \\
\hline & Peak height & 281.544 & 101.711 & 202.668 & 757.213 \\
\hline
\end{tabular}

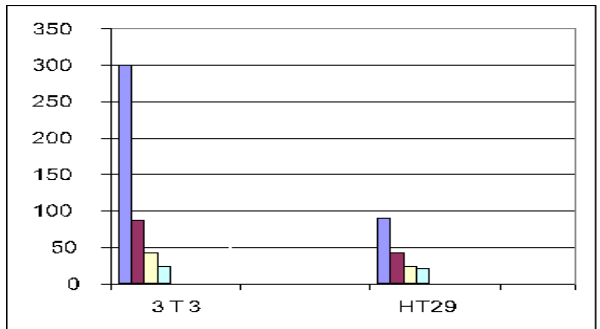

Figure 5. Densitometry analysis of molecular weights IBMR3 $\mathrm{Ag}$ with $3 T 3$ and HT29 cell line

\subsubsection{Peak Height Graphs of 3 T3 and HT29 IBMR3 Antigens}

Graph d) 3T3, with four characterized peak heights (1856.985, 551.769, 394.164, and 216.185) the highest peak height was in number 1, (1856.985), further the highest from all the peak height in HT29 sample as shown in Table 4, Graph (d). and figure 6.

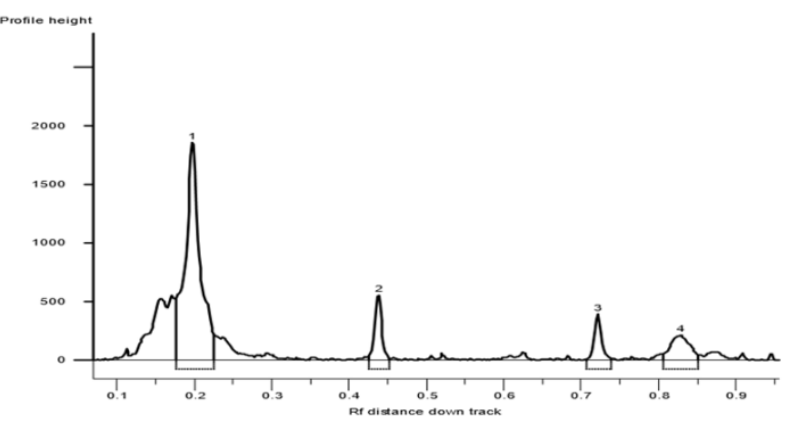

(d)

Graph d. 3 T3 densitometry

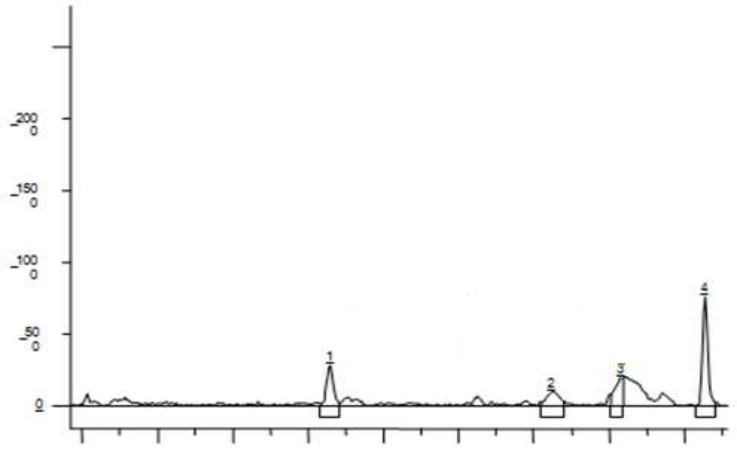

(e)

Graph e. HT29 densitometry

Graph e) HT29, with four characterized peak heights (281.544, 101.711, 202.668, and (757.213). The highest peak height in number 4 with (757.213).As in table 4, Graph e, and figure 6.

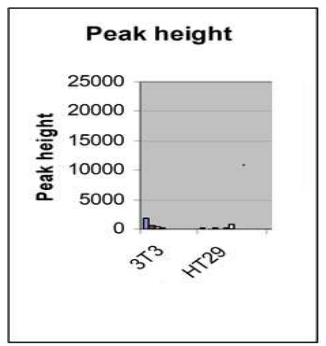

Figure 6. Densitometry of $3 T 3$ and HT29 protein samples for peak height with cell lines in PVDF membrane

\subsubsection{T3 and HT29 Densitometry of IBMR3 Antigens Raw Volume (Protein Band Concentration)}

The results of raw volume for cell lines can be seen in foure bands in Table 4, and Figure 7 have shown the value of raw volume (The amount of protein presents in the band. 
The greater (contains more protein concentration) was the height concentration in the first band of $3 \mathrm{~T} 3$ cells 1460168.75 and the lowest concentration was 76106.84 in the second band of HT29.

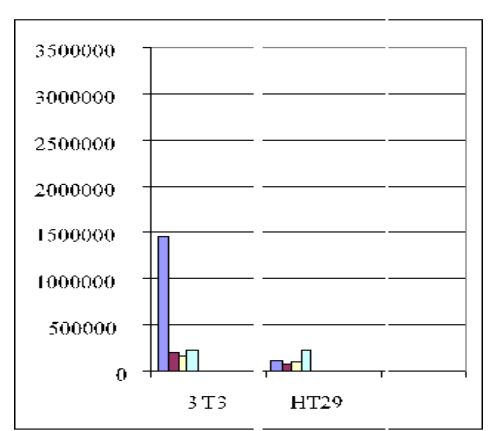

Figure 7. Analysis of cell lines IBMR3 $\mathrm{Ag}$ raw volume (protein concentrations) in densitometry

\section{Discussions}

This is the first study to determine and analyse specific IBMR3 antigen level in 3T3 and HT29 cell lines. There is a possibility that $\mathrm{mAb}$ IBMR3 may be binding to similar molecules. The variation in the relative molecular weight of the IBMR3 antigens in these two samples indicated that the recognized antigens may be the different domains of the same molecule, or the same liner domain present on different types of molecules (Mat, 1992: Galizzi et al., 1990).

Nevertheless mAb IBMR3 is proven as a useful reagent for the study of cells. The different values in molecular weights of cell lines may be due to the relation between glycosylation reactions in the antigen and antibody protein cells membrane (Paulick and Bertozzi, 2008) glycosylation has relation of connection between antibody and antigen membrane (Mat, 1992: Galizzi et al., 1990): (Ferguson and Williams, 1988) :(Kinoshita and Inoue, 2000).

\section{Conclusions}

The results from this study suggest that the IBMR3 antigens were expressed in both 3T3 and HT29. However, the expression pattern varied from sample to sample. This might be indicative of different expression profiles of this antigen, as recognized by the antibody that gave different reading in the IBMR3 expression, because results showed different molecular weight in different bands in samples. This might also be indicative of the fact that IBMR3 antibody can express or recognize the same epitopes in different molecules having different relative molecular masses.

\section{Recommendations}

MAb IBMR3 have potential to be useful for identify and study the roles of these molecules in cancers tissue. This expression profile can be applied to human tissue to detect more specific antigens that might help to use IBMR3 as a marker for cancer diagnosis in the future.

\section{References}

[1] Boersma, W. J. A., Claassen, E., Deen, C., Gerritse, K., Haaijman, J. J. and Zegers, N. D. (1988) Antibodies to short synthetic peptides for specific recognition of partly denatured protein. Analytical chemistry Acta, 213, 187- 197.

[2] Galizzi, J. P., Zuber, C.E., Cabrillat, H., Gorman, M., Djossou, O., Kastelin, R.and Banchereau, J. (1990) Molecular cloning of a cDNA encoding the human interleukin-4 receptor. International Immunology, 2, 669675 .

[3] Hara, Y and Mat, I.B. (2004) Differential expression of IBMR3 antigens in normal and transformed cells. Medimond International Proceedings: Immunology, E7 18C4844, 229- 233.

[4] Hawkins, R.E., Llewelyn, M.B. and Russell, S.J. (1992) Adapting antibodies clinical use. Biomedical Journal, 305, 1348-1352.

[5] Kaspar, R. (1997) Western Blotting (a laboratory protocol).

[6] Kinoshita, T., Inoue, N. (2000) Dissecting and manipulating the pathwayfor glycosylphosphatidylinositol-anchor biosynthesis. Curr Opin Chem Biol, 4,632-638.

[7] Laemmli, U.K. (1970) Cleavage of structural proteins during the assembly of the head of bacteriophage T4. Nature, $227,680-685$.

[8] Molina, H., Holers, V. M., LI, B., Fang, Y-F., Mariathsan, S., Goellner, J., Strauss-Schoenberger, J., Karri, R.W., and Chaplin, A. D. (1996) Markedly impaired humoral immune response in mice deficient in complement receptors 1 and 2. Proceedings National Academy of Sciences of the United States of America, (93), 3357-3361.

[9] Mat, I.B. (1992) Analysis of human interleukin-4 receptorassociated molecules (gp200-MR6 molecule) in normal and transformed epithelia. PhD thesis, London: University of London, 244- 277.

[10] Murillo, O., Arina, A., Tirapu, I., Alfaro, C., Mazzolini, G., Palencia, B., López-Diaz De Cerio, A., Prieto, J., Bendandi, M. and Melero, I. (2003) Potentiation of Therapeutic Immune Responses against Malignancies with Monoclonal Antibodies. Clinical Cancer Research. (9), 5454-5464.

[11] Paulick, M.G., Bertozzi, CR. (2008) the glycosylphosphatidylinositol anchor: A complex membraneanchoring structure for proteins. Biochemistry, 47, 69917000 .

[12] Reichert, J., M. and Valge-Archer, V., A. (2007) Outlook: Development trends for monoclonal antibody cancer therapeutics, Nature Reviews Drug Discovery, 6, 349-356.

[13] Shapiro, A.L., Vinuela, E.and Maizel, J.V. Jr. (1967) Molecular Weight Estimation of Polypeptide Chains by Electrophoresis in SDS Polyacrylamide Gels. Biochemical and Biophysical Research Communications, 28(5), 815-820.

[14] Stryer, L. (1996) Biochemistry. New York: W.H. Freeman, 62. 
[15] Spinks, C.A. (2000). Broad-specificity immunoassay of low molecular Weight food contaminants new paths to Utopia Trend. Food Science and Technology, 11, 210-217.

[16] Towbin, H., Staehekin, T. and Gordon, J. (1979) Electrophoretic transfer of proteins from polyacrylamide gels to nitrocellulose sheets: procedure and some applications. Proceedings National Academy of Sciences of the United States of America, 76(9), 4350-4354.
[17] Walter, G. and Doolittle. (1983) Antibodies against synthetic peptides. Genetic Engineering, 61-6

[18] Abbreviations: mAb (monoclonal anti body), HRP (horse radish peroxidase), PVDF (Polyvinylidene difluoride membrane), IgG (Immunoglobulin G), IgM (Immunoglobulin M), (IgS Immunoglobulin S). IL-4 (Human Interleukin - 4. recapture) 